\title{
ERRATA AND CORRIGENDUM
}

\section{ERRATA}

In Fred Sommers' “Structural Ontology" (Vol I, pp. 21-42), diagrams $\mathrm{V}$ and $\mathrm{VI}$ on p. 33 should be corrected to:

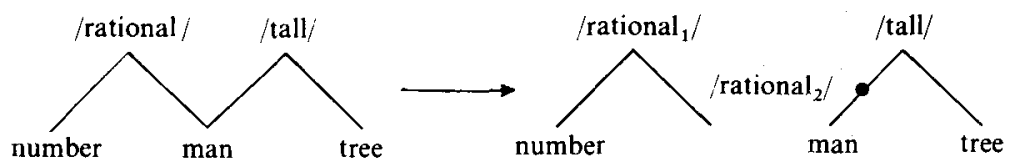

Figure V

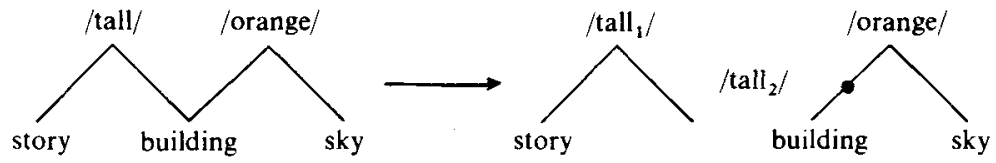

FiguRE VI

In John Bacon's "The Subjunctive Conditional As Relevant Implication" (Vol I, pp. 61-80) the following corrections are to be noted:

P. 67 lines 9 and 1 from bottom, p. 68 line 1, and p. 78 note 11 , for ' $\rightarrow$ ' read ' 3 '. P. 79 note 17 , line 6, delete 'to be'. P. 80 Meyer \& Dunn, replace ' $T$ ' by ' $\gamma$ '. In p. 80 Myhill, insert ' $\supset$ ' between single quotes, and in p. 80 Moh, replace 'Methodos' with 'Methodos.'

The editors deeply regret these errors.

\section{CORRIGENDUM}

Professor Eddy M. Zemach asked the editors to make the following correction in his "Existence, Reference and Meaning" 